\title{
The theory of degradation for polymer concrete in complex stress state
}

\author{
Yuliya Moreva ${ }^{1}$, Andrey Varlamov $^{*}$, and Yuliya Novoselova ${ }^{1}$ \\ ${ }^{1}$ Magnitogorsk State Technical University, Department the design of structures, 455000, 38 Lenin \\ Ave, Magnitogorsk, Russia
}

\begin{abstract}
The article discusses the features of the application of the theory of degradation to the work of an integrated structure operating in a complex stress state. The analysis of the work of an integrated structure consisting of a steel shell filled with concrete (core structure). Based on the analysis of the construction work, we obtained the relations connecting the deformations of the steel shell and the polymer concrete core of the complex structure. The obtained relations made it possible to apply the diagrams of concrete work for uniaxial compression to analyze the possibility of using concrete as a core of an integrated structure. Experimental studies of the polymer concrete core of the structure were conducted. In total, ten concrete compositions were made and investigated. The compositions of concrete differed in cementitious: cement and polyester resin. As a filler used sand, gravel, ground clay, marble flour, soda and fine mineral fibers. Samples were tested for central and eccentric compression. During the tests used the methods used in testing cement concrete. As a result of the tests, complete schedules of the work of materials for uniaxial compression were obtained. The analysis of the energy characteristics of concrete schedules based on the theory of degradation is carried out. As a result of the discussion of the results obtained, conclusions are drawn about the possibility of using polymer concrete as the supporting core of an integrated structure with an external steel shell.
\end{abstract}

\section{Introduction}

A composite system, consisting of an external steel shell filled with concrete, is an effective supporting building structure $[1,2]$. This design has many potential possibilities and allows you to combine materials with various deformation and strength characteristics. Polymer concrete, having high deformative, strength and protective properties, can enhance the work of the composite system [3-6]. It is required to evaluate the work in the complex. Steel shell - polymer concrete. Evaluation and calculation of the resource of building structures is currently given special attention [7-10]. An assessment of the work of an integrated design is most efficiently carried out on the basis of the energy theory of degradation $[11,12]$.

${ }^{*}$ Corresponding author: mgrp@mgn.ru 


\section{Analysis of the work of the concrete structure}

In the limiting state of operation of the concrete structure, there is a mutual pressure of the core on the shell on the one hand, and the pressure of the shell on the core on the other. The simplest dependence suitable for the analysis of such behavior in most studies is described by the formula [13]

$$
N=\left(R_{\mathrm{b}}+k \mu R_{\mathrm{s}}\right) A_{b}+R_{\mathrm{s}} A_{\mathrm{s}},
$$

$R_{b}$ is the concrete core strength of the structure, $R_{s}$ is the uniaxial tensile strength of the steel shell; $\mu$ is the percentage of transverse reinforcement; $\mathrm{k}$ is the coefficient of efficiency of indirect reinforcement; $A_{b}, A_{s}$ - the cross-sectional area of the shell and concrete core. It follows that the coefficient $\mathrm{k}$ is determined by the formula:

$$
k=\left(N-R_{\mathrm{s}} A_{\mathrm{s}}-R_{b}\right) / \mu R_{\mathrm{s}} .
$$

The analysis of the given dependences and the known experimental results [14] show that with an increase in the prismatic strength of the concrete core, the value of the coefficient $\mathrm{k}$ also increases. With an increase in the percentage of reinforcement, the coefficient $k$ decreases. Such changes occur for a concrete core with a strength of $R_{b}=5$ $\mathrm{MPa}$ ranging from 0,342 to 1,18 , for a concrete core with $\mathrm{R}_{\mathrm{b}}=32 \mathrm{MPa}$ from 0,84 to 2,222 and for a concrete core with $\mathrm{R}_{\mathrm{b}}=45 \mathrm{MPa}$ from 1,037 to 2,515.

As the results of the experiments show, when loading Tube Confined Concrete structures, a significant redistribution of stresses occurs between the Tube Confined Concrete core and the reinforcement. Moreover, the redistribution of stresses during central compression more clearly occurs with increasing shell thickness (transverse reinforcement). For eccentrically loaded items, redistribution always occurs. Significant deformability of samples with indirect reinforcement leads to the need to assess their bearing capacity, limiting it to the yield strength of the pipe material in the longitudinal or transverse direction. However, for a complex building element, such as a Tube Confined Concrete structure, it is most rational to analyze its operation according to the full diagram of the material's behavior under load, and to take the ultimate force value depending on the specific design conditions for a given deformation or displacement. For example, by the simplest formula (1) for $\mathrm{k}=2$.

From the preconditions discussed above, the need to build a concrete work diagram in conditions of constraining its transverse deformations is seen. To do this, we consider the linear relationship between stress and strain described by law of elasticity. The possibility of using a linear relationship between the growth of longitudinal strains and lateral pressure was pointed out by Berg [15]. Recent works [16] have confirmed this possibility. If the element under consideration is subjected to the simultaneous action of normal stresses $\sigma_{1}>$ $\sigma_{2}>\sigma_{3}$, uniformly distributed over its faces, then we have the relation:

$$
\varepsilon_{1}=1 / E\left[\sigma_{1}-v\left(\sigma_{2}+\sigma_{3}\right)\right],
$$

$\varepsilon_{1}$ is the engineering strain in the $\mathrm{x}$ direction; $\mathrm{E}$ is the modulus of elasticity of the material during compression of the sample; $\sigma_{1}, \sigma_{2}, \sigma_{3}$ - normal stress components parallel to the axes; $v$ is the Poisson's ratio.

Taking into account the equality $\sigma_{2}=\sigma_{3}$ due to the equality of the parameters defining $\sigma_{2}, \sigma_{3}$ in the $y, z$ direction, expression (3) takes the form:

$$
\varepsilon_{1} E=\sigma_{1}-2 k v \sigma_{2},
$$

is a coefficient depending on ultimate load and material. 
The dependent between stresses and relative deformations of concrete, taking into account only the work of the compressed branch, can be described by characteristic points in the form of a polynomial:

$$
\sigma_{1}=a+b \varepsilon+c \varepsilon^{2}
$$

a, b, c are constant parameters characterizing the material.

From the condition that the first derivative is the tangent of the angle of inclination of the tangent to the concrete strain curve and at the same time the tangent modulus, we obtain:

$$
E / R_{b}=b+c x,
$$

substituting the values from (6) into (5) and at the same time simplifying it, we write:

$$
E=\left[c\left(\sigma / R_{b}\right)+b^{2}-4 c a\right]^{-1 / 2} \times R_{b} .
$$

Placing of shear reinforcement, in contrast to hydrostatic pressure, begins to have a restraining effect on the transverse deformation of concrete only after the occurrence of transverse displacements. Moreover, the effect of the Tube Confined Concrete shell on the constraint of transverse deformations differs from the influence of spiral or mesh reinforcement. When the Tube Confined Concrete core is compressed, the effect of the pipe on the constraint of the transverse deformations of concrete will lag behind by the amount due to the difference in the transverse deformations of concrete and reinforcement $\Delta \boldsymbol{l}=\left(\varepsilon_{b} b\right.$ $\left.\varepsilon_{s} b\right)$. Comparing the Poisson's ratio for concrete and steel, it can be seen that while compressing the steel pipe and concrete core, the containment of transverse deformations of concrete begins to occur after the surface of the concrete core reaches the cage wall. This is due to an increase in the coefficient of transverse deformations of concrete during loading of the Tube Confined Concrete core of the concrete structure. In turn, the growth of transverse strains is due to the appearance and development of cracks.

It has been established that during compression of concrete processes of compaction, decompression and destruction of its structure occur. As stresses increase above a certain limit, micro fractures begin to develop in concrete, which, with an increase in load, develop into micro cracks and macro fractures.

During loading of a Tube Confined Concrete sample, at least two parametric points can be fixed. The first of them $R_{m}^{0}$ is the lower conditional boundary of micro crack formation, the second $R_{m}^{v}$ is the upper conditional boundary of microcracking, starting with which the process of loosening of the structure prevails over compaction.

This type of graphic dependence can be described by a parabola of the form [10]:

$$
y=a+(b+x)^{2}
$$

Using characteristic points, we rewrite equation (8) in the form:

$$
\begin{aligned}
& \mathrm{v}_{b}=0,5\left[\frac{\sigma_{1}}{R_{b}}+\left(\sqrt{2 \mathrm{v}_{0}} \frac{R_{m}^{\mathrm{v}}}{R_{b}}-\frac{R_{m}^{0}}{R_{b}}\right) \cdot\left(1-\sqrt{2 \mathrm{v}_{0}}\right)^{-1}\right] \cdot\left[\frac{R_{m}^{\mathrm{v}}}{R_{b}}+\left(\sqrt{2 \mathrm{v}_{0}} \frac{R_{m}^{\mathrm{v}}}{R_{b}}-\frac{R_{m}^{0}}{R_{b}}\right) .\right. \\
& \left.\left(1-\sqrt{2 \mathrm{v}_{0}}\right)^{-1}\right]^{-2} \text { (9) }
\end{aligned}
$$

$v_{0}$ is the initial transverse strain coefficient.

Parametric points $\mathrm{R}_{\mathrm{T}}^{0}$ and $\mathrm{R}_{\mathrm{T}}^{v}$ can be determined from the data obtained by Berg in [10]:

$$
\left\{\begin{array}{c}
R_{m}^{v}=\left(0,35 \lg R_{b}+0,175\right) \times R_{b} \\
R_{m}^{0}=\left(0,35 \lg R_{b}-0,15\right) \times R_{b}
\end{array} .\right.
$$


The resulting expression is valid for changing the coefficient of transverse deformation of concrete without placing of shear reinforcement. Placing of shear reinforcement reduces lateral deformation of concrete. However, in the future, we will assume that this occurs in proportion to the change in $\boldsymbol{v}$ for concrete without placing of shear reinforcement.

Consider the work of the Tube Confined Concrete element based on the graphs of deformation of concrete and reinforcement. For this, we construct experimental graphs of the absolute transverse deformations of concrete and reinforcement. The obtained graphs are shown in figure 1. As can be seen from the obtained graphs, the cage begins to restrain deformations at first of the weakest concrete (intersection of curves 1 and 4) then of concrete with a strength of $32 \mathrm{MPa}$, and the concrete with a strength of $45 \mathrm{MPa}$ begins to affect the containment effect at a loading level exceeding $70 \%$ of its prismatic strength. The restraining effect of the shell is most pronounced on weak concrete. We can see that the strain curve is much stretched.

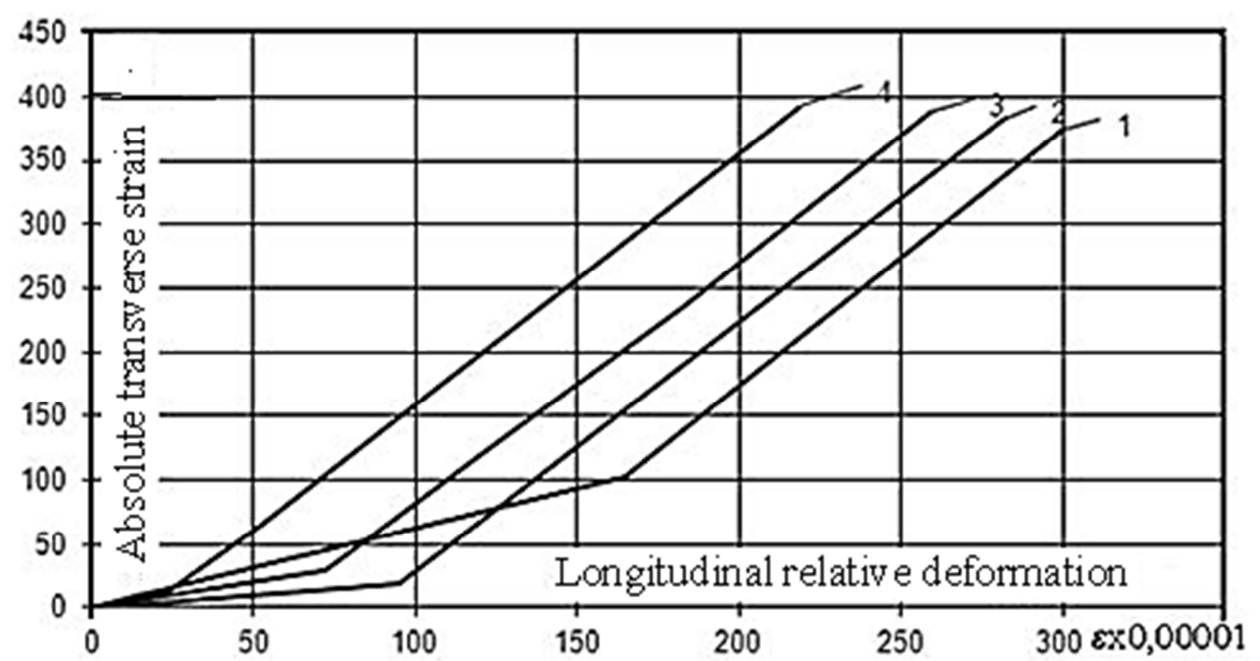

1-transverse deformation of the steel shell; 2-transverse concrete deformation without taking into account placing of shear reinforcement $t$ with $\mathrm{R}_{\mathrm{b}}=5 \mathrm{MPa}$; 3-transverse concrete deformation without taking into account placing of shear reinforcement with $\mathrm{R}_{\mathrm{b}}=32 \mathrm{MPa}$; 4-transverse deformation of concrete without taking into account placing of shear reinforcement with $\mathrm{R}_{\mathrm{b}}=45 \mathrm{MPa}$;

Fig. 1. Graphs of the dependence of absolute transverse deformations on longitudinal relative ones.

Accordingly, the graphs show that when the yield stresses in the steel shell are reached, the value of the restraining stresses on concrete can be considered constant in the future.

Starting from this moment, the stresses $\sigma_{3}$ can be taken constant and equal to $\mathrm{R}_{\mathrm{s}}$. Up to this point, the restraining effect of indirect reinforcement increases linearly, starting from the intersection of the curves. Summarizing the analysis, we write the value of the pressure of reinforcement on concrete in the form:

$$
\sigma_{3}=\Delta \varepsilon E_{s}=E_{s}\left(v_{b} \varepsilon_{1}-v_{s} \varepsilon_{1}\right)=E_{s} \varepsilon_{1}\left(v_{b}-v_{s}\right),
$$

$\mathrm{E}_{\mathrm{s}}$ is the modulus of elasticity of steel; $\Delta \varepsilon=\Delta \mathrm{l} / \mathrm{b}$ is the difference in transverse deformations of steel and concrete; $\boldsymbol{v}_{\boldsymbol{b}}, \boldsymbol{v}_{\boldsymbol{s}}$ are the transverse strain coefficients of concrete and steel, respectively.

Using the results of analysis of the behavior of concrete with placing of shear reinforcement, for a concrete core with indirect reinforcement with clamps:

$$
\sigma_{3}=\Delta \varepsilon \mathrm{E}_{\mathrm{s}}=\mathrm{E}_{\mathrm{s}} v_{\mathrm{b}} \varepsilon_{1}\left(v_{\mathrm{b}}=0,2\right)
$$


Compare the deformability of concrete cores. As can be seen from the above analysis, to assess the effectiveness of the applicability of polymer concrete as the core of the Tube Confined Concrete structure, it is sufficient to study the behavior graphs of the material under uniaxial compression.

\section{The need to study the behavior of the concrete core}

The experimental and theoretical analysis revealed the need to study the behavior of a separate concrete core with the construction of diagrams of its deformation.

Next, we describe the results of a study of the behavior of a concrete core on concrete with different composition and type of binder. In particular, we use a polymer as a binder. Such a material has its own characteristics during deformation, which will make it possible to more clearly reveal the work of the Tube Confined Concrete core. Since in modern standardization there are no requirements for testing polymer concrete, we used the regulatory framework for testing concrete with a cement binder.

The arrangement of the material is adopted in accordance with the technology of the experiment, which should facilitate its use in practice.

\section{The compositions of polymer concrete mixtures for samples}

For the preparation of polymer concrete mixtures, the compositions were used, which are presented in Table 1. For each type of concrete, 6 pieces of samples were made. The total number of samples is presented in Table 2 .

Table 1. Characteristics of polymer concrete mixtures

\begin{tabular}{|c|c|c|c|c|c|}
\hline № & Sample Composition & Ratio of parts & $\rho, \mathrm{kg} / \mathrm{l}$ & $\mathrm{M}, \mathrm{kg}$ & $\begin{array}{l}\rho, \mathrm{kg} / \mathrm{M}^{3} \\
\text { concrete }\end{array}$ \\
\hline 1 & mastic gum / stream sand & $100 / 500$ & $1140 / 1440$ & $114 / 720$ & 1665 \\
\hline 2 & mastic gum / stream sand / slag wool & $100 / 500$ & $1140 / 1440$ & $114 / 720$ & 1665 \\
\hline 3 & mastic gum / enriched clay /glass sand & $100 / 200 / 200$ & $1140 / 1490 / 1500$ & $114 / 298 / 300$ & 1475 \\
\hline 4 & mastic gum / enriched clay /glass sand / natron & $100 / 200 / 200$ & $1140 / 1490 / 1500$ & $114 / 298 / 300$ & 1425 \\
\hline 5 & mastic gum / marble powder/glass sand & $100 / 250 / 250$ & $1140 / 1333 / 1500$ & $114 / 333 / 375$ & 1625 \\
\hline 6 & mastic gum / marble powder /glass sand / natron & $100 / 250 / 250$ & $1140 / 1333 / 1500$ & $114 / 333 / 375$ & 1575 \\
\hline 7 & mastic gum / marble powder/glass sand / slag wool & $100 / 250 / 250$ & $1140 / 1333 / 1500$ & $114 / 333 / 375$ & 1625 \\
\hline 8 & mastic gum / stream sand /crushed stone $10-20 \mathrm{~mm}$ & $100 / 500 / 250$ & $1140 / 1440 / 1320$ & $114 / 720 / 330$ & 1525 \\
\hline 9 & mastic gum & 100 & 1140 & 100 & 1140 \\
\hline & concrete (cement М400) Ц:П:Щ:В & 1:0.7:2:0.39 & - & - & 2441 \\
\hline
\end{tabular}

Table 2. Nominal dimensions and number of tested samples.

\begin{tabular}{|l|c|c|}
\hline Sample shape & Sample size & Quantity \\
\hline third power & $100 \times 100 \times 100$ & 48 \\
\hline small prism & $40 \times 40 \times 1600$ & 54 \\
\hline prism & $100 \times 100 \times 400$ & 120 \\
\hline
\end{tabular}


A total of 10 sample compositions were manufactured. For the preparation of polymer concrete solutions, aggregates with a maximum grain size of fractions up to $1 \mathrm{~mm}$ were used: $50 \%$ of fine fractions $(0,5-0,7 \mathrm{~mm}), 50 \%$ of the finest fractions (less than $0,1 \mathrm{~mm}$ ). The binder in the samples is polyester resin. For samples with sand and crushed stone, ordinary river sand $(0-5 \mathrm{~mm})$ and crushed stone of a fraction of $0 \ldots 20$ were additionally used. The same materials were used in the manufacture of concrete with a cement binder. Due to the limited number of molds, one formulation was made in one day. Samples from forms in three days. The following composition was made seven days after sample extraction. Such a period of time made it possible to prepare and test all manufactured samples at equal times. Tests of the samples were carried out at the age of 28-30 days. The test methodology was consistent with the methodology for testing concrete samples adopted in Russia. Part of the prisms to identify the effect of the greatest deformations was tested with an eccentricity of $1 \mathrm{~cm}$. The test results were subjected to statistical processing in accordance with the Norms accepted during testing.

\section{Results}

The generalized test results are shown in table 3. The appearance of some samples after failure is shown in figure 2. Graphs of deformation of concrete of different compositions are shown in figures 3 and 4 .

Table 3. Summary table of the strength characteristics of concrete with various fillers

\begin{tabular}{|c|c|c|c|c|c|c|c|}
\hline № & $\begin{array}{c}\text { Sample, sm } \\
\text { Characteristic }\end{array}$ & $\begin{array}{c}\text { 10x10x10 } \\
\boldsymbol{R}, \\
\text { МПа }\end{array}$ & $\begin{array}{c}4 \times 4 \times 16 \\
\boldsymbol{R}_{\boldsymbol{b}}, \\
\text { МПа }\end{array}$ & $\begin{array}{c}\text { 10x10x40 } \\
\boldsymbol{R}_{\boldsymbol{b}}, \\
\text { МПа }\end{array}$ & $\begin{array}{l}10 x 10 \times 40 \\
\text { (eccentr.) } \\
\boldsymbol{R}_{\boldsymbol{b}}, \text { МПа }\end{array}$ & $\begin{array}{c}10 \times 10 \times 400 \\
(\text { cracks) } \\
\mathbf{N} / \mathbf{N}\end{array}$ & $\begin{array}{c}\text { Relative } \\
\text { value }\end{array}$ \\
\hline 1. & Mastic gum, sand & 57.7 & 41.3 & 57.4 & - & 1 & 6.4 \\
\hline 2. & Mastic gum, sand, slag wool & 52.5 & 53.7 & 51.1 & - & 1.3 & 6.5 \\
\hline 3. & Mastic gum, clay, sand & 65.2 & 62.5 & 61 & 61.1 & 0.9 & 7.4 \\
\hline 4. & Mastic gum, clay, sand, natron & 38.9 & 36.6 & 33.4 & - & 0.8 & 7.4 \\
\hline 5. & Mastic gum, marble powder, glass sand & 77.8 & 76 & 68.2 & 58.9 & 0.9 & 6.6 \\
\hline 6. & $\begin{array}{l}\text { Mastic gum, marble flour, glass sand, } \\
\text { natron }\end{array}$ & 73.1 & 71.9 & 65 & 42 & 0.9 & 6.6 \\
\hline 7. & $\begin{array}{l}\text { Mastic gum, marble powder, } \\
\text { glass sand, slag wool }\end{array}$ & - & 108.6 & - & - & - & 6.7 \\
\hline 8. & $\begin{array}{l}\text { Mastic gum, stream sand, } \\
\text { crushed stone fractions } 10-20 \mathrm{~mm}\end{array}$ & 63.5 & 37.5 & 63.8 & 30.9 & 1,1 & 4.2 \\
\hline 9. & Mastic gum & - & 27.5 & - & - & - & 31.7 \\
\hline 10 & Concrete & 41.4 & - & 34 & - & 0.6 & $\begin{array}{l}1(3600 \\
\text { Rubles) }\end{array}$ \\
\hline
\end{tabular}
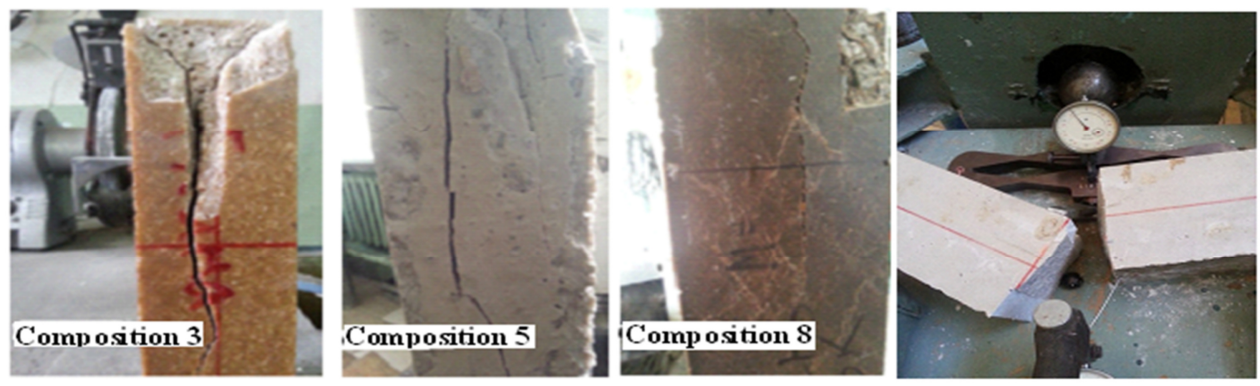

Fig. 2. View of samples after testing. 

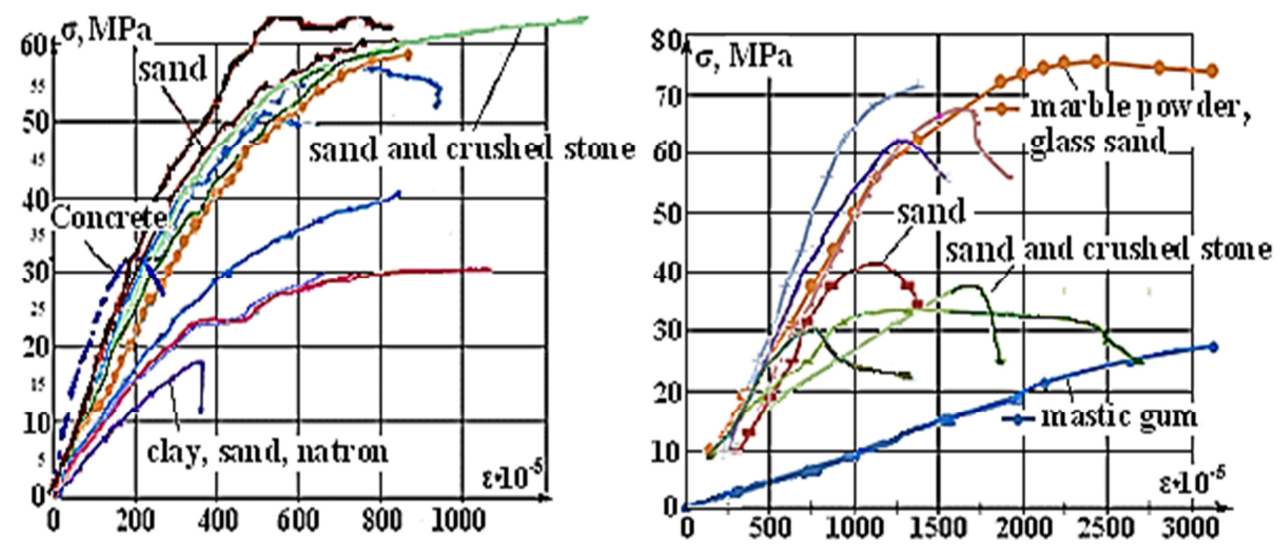

Fig. 3. Summary plot of longitudinal strain on prism compression 100x100x400 mm (left) and prisms 40x40x160 mm (right).

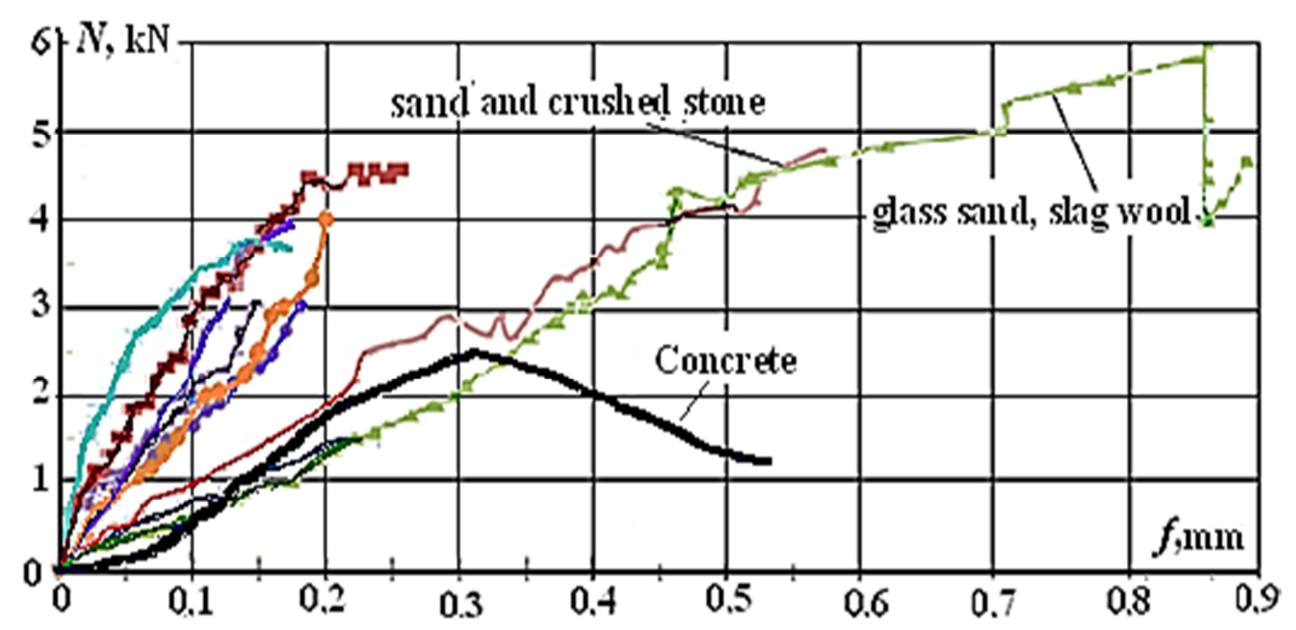

Fig. 4. General prism test schedule for crack resistance.

\section{Evaluation of the energy parameters of the Tube Confined Concrete, shell and core structure}

To assess the energy parameters of the Tube Confined Concrete and its components, we use the model of the theory of degradation, revealing the plastic properties of the object and its ability to crack resistance. The dependence is written in the form revealing the power distribution on the concrete diagram:

$$
\boldsymbol{\sigma}=[B L \ln \varepsilon-B \varepsilon+(B \alpha-B L \ln \alpha)]+\left[\frac{C L}{2} \ln \varepsilon-\frac{C}{4 L} \varepsilon^{2}+\left(\frac{C \alpha^{2}}{4 L}-\frac{C L}{2} \ln \alpha\right)\right] .
$$

In the proposed model, $\mathrm{L}$ is the deformation of the element corresponding to its strength; $\mathrm{B}$ and $\mathrm{C}$ are the energy characteristics of the object, and a is the value of the initial zone of elastic work of concrete. Table 4 shows the data on polymer concrete diagrams processed by formula (18) obtained in our tests. For comparison, the characteristics of steel, concrete, high-strength concrete and a complex Tube Confined Concrete structure are given. 
Table 4. Energy parameters of the diagrams.

\begin{tabular}{|c|c|c|c|c|c|c|c|c|c|}
\hline characteristic & $\begin{array}{c}\text { Mastic } \\
\text { gum }\end{array}$ & $\begin{array}{c}\text { Crushed } \\
\text { stone } \\
\text { and sand }\end{array}$ & clay & $\begin{array}{c}\text { marble } \\
\text { and sand }\end{array}$ & sand & B30 & B100 & $\begin{array}{c}\text { high } \\
\text { strength } \\
\text { steel }\end{array}$ & $\begin{array}{c}\text { Tube } \\
\text { Confined } \\
\text { Concrete }\end{array}$ \\
\hline 1 & 2 & 3 & 4 & 5 & 6 & 7 & 8 & 9 & 10 \\
\hline $\mathrm{R}_{\mathrm{m}}, \mathrm{MPa}$ & 29 & 64 & 61 & 68 & 51 & 22 & 71 & 845 & 150 \\
\hline $\mathrm{C}$ & 5848 & 7277 & 35630 & 11603 & 13532 & 25945 & 115410 & -330140 & -28992 \\
\hline $\mathrm{B}$ & -3294 & -2745 & -18670 & -5600 & -5241 & -11159 & -59341 & +23382 & +22978 \\
\hline$\alpha$ & ----- & 33.5 & ----- & 94 & 51 & 7.1 & ---- & 26 & 48 \\
\hline
\end{tabular}

The energy characteristics of the materials were divided into two groups. All concretes have a positive value of characteristic $\mathrm{C}$ and a negative value of characteristic B. Highstrength steel and Tube Confined Concrete stand out in another group. Cement concretes with close prismatic strength are more fragile compared to polymer concrete. In terms of the elastic zone, a-polymer concrete, steel and Tube Confined Concrete are in the same group.

\section{Discussion}

The research results are visible from a comparison of the test results of the individual compounds. The external nature of the destruction of all composite samples was the same. As evidenced by the photographs of the destroyed samples. However, the destruction of binders (cement and mastic gum) was very different from each other. The destruction of a prism made of pure resin was mainly plastic in nature: the prism under the load was compressed twice, after that it began to bend and only after bending did a crack appear in it. However, as can be seen from the table, the strength of the resin was 1,5 times less than the strength of the cement binder.

A cement binder, similar in its characteristics to a solid state with a stone aggregate, has a relatively small effect on the concrete system formed as a result of synthesis (this article is not analyzed). For a binder made of polyester mastic gum, the effect of aggregate is critical. The compressive strength of polymer concrete samples is much higher than the compressive strength of the polymer - $2 \ldots 3$ times. The strength of polymer concrete on different components is approximately the same and depends on the homogeneity of the mixture in some cases, the heterogeneity significantly reduced the strength. The deformability of polymer concrete has decreased compared to the deformability of pure mastic gum. Relativity of deformations at such large values of the plastic component ceases to make sense. However, the deformability of polymer concrete is $5 \ldots 6$ times higher than the deformability of ordinary concrete with a cement binder (Figure 8).

Ultrasonic investigations did not reveal crack growth in polymer concrete with a fine aggregate up to the start of fracture of the samples. In samples with sand and gravel aggregate, changes were noted at loads exceeding 0.8 from destructive. The deformations in this case exceeded the deformations of ordinary concrete by more than three times.

Due to the finely ground medium and high strength, fracture of the samples during fracture toughness tests was brittle. In this case, the strength of the samples doubled. When large components were added to the concrete, limiting the growth of cracks, the destruction began to occur plastic, and the strength increased by more than three times.

\section{Conclusion}

1. The use of polymer concrete as the core of Tube Confined Concrete columns is effective, but only from the point of view of comparison with the behavior of ordinary concrete: high 
strength with conventional manufacturing technology; significant deformability, which allows the use of high-strength steels without taking into account the "cage effect"; high lateral deformability, allowing you to include an external clip in the work of the complex element; late crack resistance, which increases the efficiency of the clip.

2. Energetically, the Tube Confined Concrete core made of cement concrete and polymer concrete is compatible with the integrated pipe concrete structure.

3 . The high cost of polymer concrete (table 3) forces the use of polymer concrete in conventional pipe concrete structures only in special cases. It is advantageous to use thinwalled effective structures made of polymer concrete. Polymer concrete itself can serve as the outer shell of a Tube Confined Concrete structure or be a protective shell of an integrated structure.

\section{References}

1. N.I. Karpenko, V.A. Eryshev, V.I. Rimshin, IOP Conference Series: Materials Science and Engineering, 463(3),032024 (2018)

2. A.A. Varlamov, V.B. Gavrilov, A.I. Sagadatov, BST, 11, 29-31 (2017)

3. A.A.Varlamov, V.I.Rimshin, S.Y.Tverskoi, IOP Conference Series: Materials Science and Engineering, 463(2), 022028 (2018)

4. A.A.Varlamov, V.I. Rimshin, S.Y. Tverskoi,_Materials Science Forum, 931, 340$345(2018)$

5. A.A. Varlamov, Concr. Reinforce. concr., 3, 27-30(2012)

6. V.I. Rimshin, A.A. Varlamov, News High. Educ. Establish. Techn. Ser. Text. Ind. 3, 63-68 (2018)

7. A.A. Varlamov, V.I. Rimshin, S.Y. Tverskoi, IFAC-PapersOnLine, 51(30), 808-811 (2018)

8. A.A.Varlamov, V.I.Rimshin, S.Y.Tverskoi, IOP Conference Series: Materials Science and Engineering, 463(2), 022029 (2018)

9. V.I. Rimshin, E.A.Larionov, N.T. Vasylkova, Struct. Mech. Engine. Struct. 2, 77$81(2012)$

10. Y.M. Bazhenov, V.T. Erofeev, V.I. Rimshin, S.V. Markov, V.L. Kurbatov, Engin. Solid Mech. 4(4), 219-225 (2016)

11. A.A.Varlamov, V.I.Rimshin, Behaviors of concrete. The General theory of degradation (Moscow, INFRA-M) p 436 (2019)

12. E.Kuzina, V.Rimshin, V. Kurbatov, IOP Conference Series: Materials Science and Engineering, 463(4), 042009 (2018)

13. G. Murashkin, D Panfilov, V Murashkin, J. Civ. Engin. Architec. 2, 125- 31(2013)

14. K.Z Galustov, Beton i zhelezobeton, 5, 11-15 (2008)

15. E. Kuzina, A. Cherkas, V. Rimshin, IOP Conference Series: Materials Science and Engineering, 365(3),032053 (2018)

16. A.A. Varlamov, News KGASU, 29,19-26 (2014) 